\title{
Assessment and management of a longstanding penile lesion
}

Daniel Mazzoni, Jim Muir

\section{CASE}

A man aged 60 years presented with an enlarging penile lesion that had been present for six years. He did not have pain, any symptomatology or erectile dysfunction. There was no history of sexually transmissible infections. He was in a monogamous heterosexual relationship of 20 years' duration. The patient's medical history was unremarkable, and he took no medications. On examination, a solitary $1 \mathrm{~cm} \times 2 \mathrm{~cm}$ scaling keratotic plaque was present on the glans penis. It was indurated but non-tender (Figure 1).

\section{QUESTION 1}

What are the likely diagnoses?

\section{QUESTION 2}

What would be your immediate management?

\section{ANSWER 1}

The history and presentation are most consistent with verrucous carcinoma or the more serious penile squamous cell carcinoma. A hyperkeratotic viral wart is also possible. ${ }^{1}$

\section{ANSWER 2}

The first step is to confirm the nature of this lesion by representative biopsy.
Options include a shave, incisional or punch biopsy. This is preferably performed with local infiltration of $1 \%$ lignocaine with 1:100,000-1:200,000 adrenaline using as small a dose as possible. ${ }^{2}$ Adrenaline-containing local anaesthetic is routinely and safely used in penile surgery. ${ }^{3}$ Suturing typically provides immediate haemostasis for incisional or punch biopsies. Regional lymph nodes should be palpated. Ultrasonography is indicated if squamous cell carcinoma is confirmed. ${ }^{4}$

\section{CASE Continued}

A deep and wide shave biopsy was performed. This was reported as an $18 \mathrm{~mm} \times 8 \mathrm{~mm} \times 6 \mathrm{~mm}$ specimen revealing a verrucous carcinoma extending to all margins.

\section{QUESTION 3}

What are the risks with penile biopsies?

\section{QUESTION 4}

What factors influence the risk for developing male genital neoplasia?

\section{QUESTION 5}

What is the significance of the diagnosis of verrucous carcinoma?

\section{QUESTION 6}

What treatment options are available for verrucous carcinomas?

\section{ANSWER 3}

Penile skin biopsies are generally safe procedures with minimal complications. Patients should be made aware of the pain associated with injection of anaesthetic at this site and risk of syncope. The patient should be positioned for surgery with this risk in mind. Adrenaline-containing local anaesthetic is safe for local penile injection. ${ }^{3,5}$

There are risks common to all skin biopsies including bleeding, wound infection, wound dehiscence and permanent scarring. Excessive bleeding is uncommon but more likely to occur in patients taking antiplatelet and anticoagulant medications. Infection is uncommon, but patients with diabetes and those who are immunosuppressed are at increased risk. ${ }^{6}$ Hypersensitivity to local anaesthetics may occur. ${ }^{7}$ However, local anaesthetic is generally very safe to use..$^{3,8}$

Male genital biopsy carries minimal site-specific risks. There is a risk of damage to the urethral meatus with a

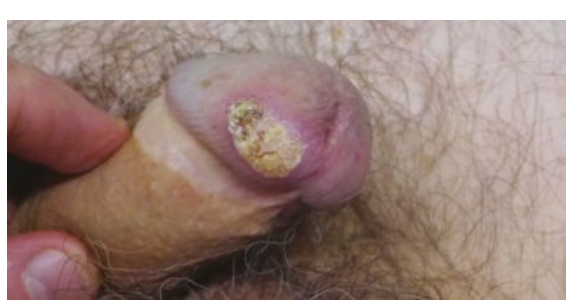

Figure 1. Patient with penile lesion 
biopsy, and scarring at this site can result in inability to accurately direct urinary stream. The risk of damage to underlying corpora cavernosum tissue is negligible as it lies deeper than a standard skin biopsy could reach, and such damage has not been reported. ${ }^{9}$ Post-procedure, there may be prolonged pain or discomfort. Rarely, damage to surrounding nerves can lead to temporary or permanent sensory loss. ${ }^{9}$

\section{ANSWER 4}

Male genital cancer most commonly affects patients aged 50-59 years. Presence of a foreskin, phimosis, poor hygiene habits, heavy cigarette smoking, human papillomavirus (HPV) infection, psoralen and ultraviolet A (PUVA) phototherapy, immunosuppression and obesity are known risk factors. Scrotal squamous cell carcinoma has been specifically associated with coal tar and chronic mechanical irritation. ${ }^{4}$ Neonatal/childhood circumcision and HPV vaccination are associated with a decreased risk. ${ }^{7}$

\section{ANSWER 5}

Verrucous carcinoma is a rare variant of well-differentiated squamous cell carcinoma associated with HPV infection. Most commonly occurring on the penis, it has also been reported in the oral cavity, anus and female genitalia. ${ }^{1}$ It is slow growing and locally aggressive but rarely metastasises. It is considered less dangerous than other squamous cell carcinomas and has a favourable prognosis, and inguinal lymphadenectomy is rarely indicated. ${ }^{1}$ Computed tomography of the pelvis may be used to evaluate inguinal and pelvic lymphadenopathy in higher-risk malignancies.

Invasion and damage to underlying soft tissue may occur, and occasionally perineural, muscle and even bone invasion. Early diagnosis and prompt management of this lesion is needed. ${ }^{10}$

\section{ANSWER 6}

Treatment of penile verrucous carcinoma is surgical excision. Most cases should be referred to a urologist or plastic surgeon for surgical management and consideration of further work-up. Consensus is still lacking for the surgical margin required. Typically, a $5 \mathrm{~mm}$ margin is used. ${ }^{11} \mathrm{It}$ is a site at which tissue conservation and preservation of form and function is important.

The role of radiotherapy is controversial because of the inability to confirm histological margin control and long-term radiation changes with this modality. ${ }^{12}$ Radiation therapy should only be employed in cases deemed not amenable to surgery. ${ }^{12}$

Local surgical resection is the mainstay of treatment. Full or partial penectomy is rarely needed and is reserved for repeated local recurrence or large or deeply invasive lesions. This ensures penile function is preserved where possible. ${ }^{1}$

Treatments such as topical 5-fluorouracil cream, imiquimod or photodynamic therapy have no role in invasive malignancy. ${ }^{9}$
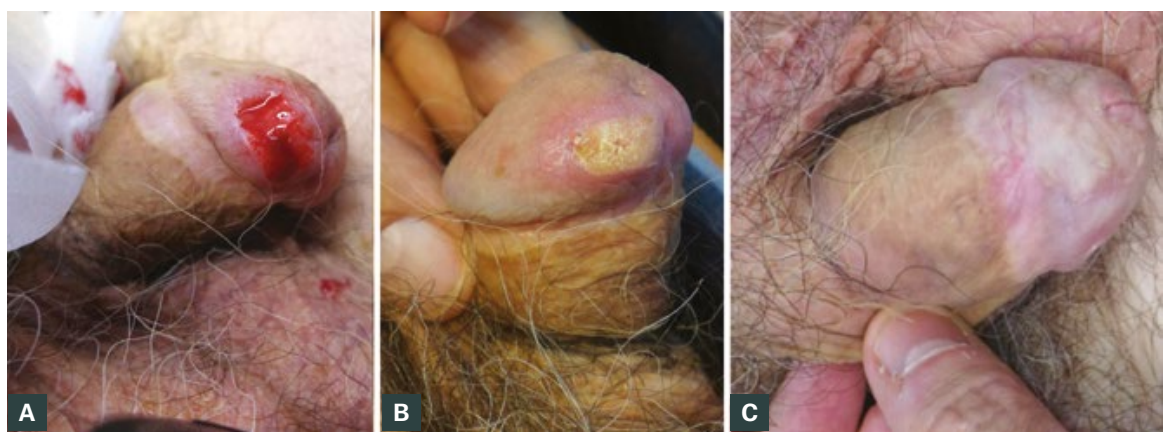

Figure 2. Lesion on the glans penis

A. Immediately post-biopsy; B. Two weeks post-biopsy; C. Four years post-treatment

\section{CASE CONTINUED}

As verrucous carcinoma has an extremely low risk of metastasis, computed tomography of the pelvis was not performed. Further excision revealed no residual lesion. The patient remained recurrence free six years post-operatively. Figure 2 illustrates his management.

\section{Key points}

- Penile biopsies are safe procedures.

- Lignocaine and adrenaline can be safely used for penile biopsies.

- Verrucous carcinoma is a low-risk malignancy amenable to simple excision.

- Local resection is the mainstay of management of invasive malignancy at this site.

\section{Authors}

Daniel Mazzoni BMedSt, MD, Basic Physician Trainee, Royal Brisbane and Women's Hospital, Qld Jim Muir MBBS, FACD, FACRRM (Hon), Consultant Dermatologist, Mater Hospital, Qld; Associate Professor, University of Queensland, Qld

Competing interests: None.

Funding: None.

Provenance and peer review: Not commissioned, externally peer reviewed.

Correspondence to:

danielmazzoni24@gmail.com

\section{Acknowledgements}

The authors would like to thank Dr David Winkle, Consultant Urologist, and Dr Anthony Hall, Consultant Dermatologist.

\section{References}

1. Li F, Xu Y, Wang H, et al. Diagnosis and treatment of penile verrucous carcinoma. Oncol Lett 2015;9(4):1687-90. doi: 10.3892/ol.2015.2909.

2. Hall A. Atlas of male genital dermatology. Cham, $\mathrm{CH}$ : Springer Nature, 2019.

3. Schnabl SM, Herrmann N, Wilder D, Breuninger $\mathrm{H}$ Häfner HM. Clinical results for use of local anesthesia with epinephrine in penile nerve block. J Dtsch Dermatol Ges 2014;12(4):332-39. doi: 10.1111/ddg.12287.

4. Heyns CF, Fleshner N, Sangar V, Schlenker B, Yuvaraja TB, van Poppel H. Management of the lymph nodes in penile cancer. Urology 2010;76(2 Suppl 1):S43-57. doi: 10.1016/j. urology.2010.03.001.

5. Wernham A, Shim TN. Survey of dermatologists and venereologists shows varying approach to penile biopsies. J Clin Aesthet Dermatol 2017;10(10):26-27.

6. Abhishek K, Khunger N. Complications of skin biopsy. J Cutan Aesthet Surg 2015;8(4):239-41. doi: 10.4103/0974-2077.172206. 
7. Nischal U, Nischal KC, Khopkar U. Techniques of skin biopsy and practical considerations. J Cutan Aesthet Surg 2008;1(2):107-11. doi: 10.4103/09742077.44174.

8. Pires Neto PJ, Moreira LA, Las Casas PP. Is it safe to use local anesthesia with adrenaline in hand surgery? WALANT technique. Rev Bras Ortop 2017;52(4):383-89. doi: 10.1016/j. rboe.2017.05.006

9. David N, Tang A. Efficacy and safety of penile biopsy in a GUM clinic setting. Int J STD AIDS 2002;13(8):573-76.

10. Pătraşcu V, Geoloaica LG, Ciurea RN. Acral verrucous carcinoma. Curr Health Sci J 2019;45(2):235-40. doi: 10.12865/CHSJ.45.02.16.

11. Minhas $S$, Kayes $O$, Hegarty $P$, Kumar $P$, Freeman A, Ralph D. What surgical resection margins are required to achieve oncological control in men with primary penile cancer? BJU Int 2005;96(7):1040-43. doi: 10.1111/j.1464410X.2005.05769.x.

12. Chang BA, Katz S, Kompelli AR, Nathan CO. Is primary radiotherapy an acceptable treatment modality for verrucous carcinoma of the larynx? Laryngoscope 2019;129(9):1964-65. doi: 10.1002/ lary.27985. 